\title{
Transformer Health Status Evaluation Method Based on the Association Rule and Analytic Hierarchy Process
}

\author{
Xun Wan ${ }^{1}$, Kunyu Tan ${ }^{2}$, Yun Liu ${ }^{1}$, Huisheng Ye ${ }^{1}$, Shihua Zhao ${ }^{1}$, Ping Peng ${ }^{1}$ and Minfang Peng ${ }^{2}$ \\ ${ }^{1}$ State Grid Hunan Electric Power Corporation Research Institute,Changsha,China,410007 \\ ${ }^{2}$ Collge of Electrical and Information Engineering, Hunan University, Changsha, China,410082
}

\begin{abstract}
In order to build the transformer evaluation model both with objective laws and subjective initiatives, a transformer health status evaluation method is proposed based on association rules and analytic hierarchy process (AHP). By analyzing the degree of association of each individual transformer operation state quantities and type of faults, established a set of comprehensive state quantities. We introduced association rule and calculated the weight coefficients of Individual state quantity, then established a comprehensive analysis of the quantity of state-level standards and determined the amount of the comprehensive state weighting coefficient. Finally, we got real running status of transformer. Simulation results show that the state evaluation method can more accurately determine the true state of running power transformers.
\end{abstract}

Keywords-transformer; health status evaluation; association rule; Analysis Hierarchy Process (AHP)

\section{INTRODUCTION}

In recent years, with the rapid development of industrial economy in our country, the fast-growing demand for power, power supply, serious overload, transformer accident rate is increasing year by year. With the change in operating years and an increase in operating condition, power transformers may occur in various forms of failure or fault indication[1], transformer condition assessment it is reflected from its operating state of various important factors starting from the macro to the transformer run security state overall assessment, by comparing historical data shows that China's current part of power transformer condition assessment method of distribution transformers provinces overhaul costs decreased significantly[2]. Dissolved gas analysis (dissolved gas analysis, DGA) technology can accurately and reliably detect potential defects transformer progressive development. There currently proposed wavelet network method, neural networks, fuzzy clustering method, gray clustering method[4], support vector machines[5], etc. which in engineering practice has also made good results. Method of Single failure analysis are shortcomings, such as: support vector machine for troubleshooting large number of samples combined model complex, prone to misclassification, wrong classification issues. Thus, in recent years, intelligent information processing method for power system fault diagnosis and state analysis has been integrated intelligent technology to develop in the direction, integrated with two or more methods, to offset each other's defects. On the other hand, the state of power apparatus requires not only assess the fusion of smart technology, it should also consider linkages electrical equipment all detected state quantities[6]. But most have focused on the evaluation method of theory research methods, at the expense of each state quantity reflecting the transformer running state correlation analysis. While power transformer fault often not only cause a state change in the amount, so the need for change in each state of the transformer comprehensive analysis to determine the operating status of the transformer. At the same time, due to the complexity process of power transformer fault, a reflection of the measured data and its potential pitfalls transformer failure probability affiliated comprehensive analysis is also very important. Beyond the above analysis, an assessment based on transformer state association rule and AHP method was proposed[7]. Through individual state quantity of classified management, individual state quantity will contact coupling integrated into a number of comprehensive state quantity, the state quantity as an integrated whole state power transformer evaluation elements[8]. We established a comprehensive analysis of the quantity of state-level standards and determined the amount of the comprehensive state weighting coefficients.

\section{POWER TRANSFORMER COMPREHENSIVE STATES SELECTION}

There are many power transformer monitoring state quantities, if you want to evaluate the running state of transformer comprehensive and accurate, you'd better select the most representative and accurately reflects the state of the transformer to index score[9]. According to the actual production run data, Individual state quantity of power transformers pilot project can be divided into two categories, includes the Electrical tests and chemical tests state quantity. When the power transformer failure occurs, it's usually accompanied by multiple state changes. In this paper, according to the practical operating experience combined with the typical transformer fault type, preliminary to amount of comprehensive state power transformer structure into a collection of eight elements expression as follows: Comprehensive state of power transformer \{Wet insulation, Core fault , Current loop is overheating, Winding fault, Partial discharge, Arc discharge, Insulation aging, Insulating oil degradation\}. The relationship between comprehensive state 
quantity and individual state quantity are major reference "Oilimmersed transformers (reactors) State Evaluation Guidelines (Q / GDW 169-2008)" which released by the State Grid Corporation of China. We finally got the Table I which contains the relation between Individual status as well as the comprehensive state.

TABLE I. MAPPING OF COMPREHNESIVE STATES AND INDIVIDUAL STATUS

\begin{tabular}{|c|c|c|}
\hline name & $\begin{array}{c}\text { comprehensive } \\
\text { states }\end{array}$ & Individual statuses \\
\hline 1 & Wet insulation & $\begin{array}{c}\mathrm{H}_{2} \text { content } * \\
\text { Oil moisture } * \\
\text { Insulating oil dielectric loss } \\
\text { Oil Breakdown Voltage } \\
\text { Insulation resistance absorption } \\
\text { ratio } \\
\text { Polarization Index } \\
\text { Volume resistivity } \\
\text { Core insulation resistance }\end{array}$ \\
\hline 2 & Core fault & $\begin{array}{c}\mathrm{C}_{2} \mathrm{H}_{6} \text { contents* } \\
\mathrm{C}_{2} \mathrm{H}_{4} \text { contents* } \\
\text { Core grounding current } \\
\text { Core insulation resistance }\end{array}$ \\
\hline 3 & $\begin{array}{l}\text { Current loop is } \\
\text { overheating }\end{array}$ & $\begin{array}{c}\mathrm{C}_{2} \mathrm{H}_{4} \text { contents* } \\
\mathrm{CO} \text { relative gas production rate * } \\
\mathrm{CO}_{2} \text { relative gas production rate * } \\
\text { Winding DC resistance mutual } \\
\text { differences }\end{array}$ \\
\hline 4 & Winding fault & $\begin{array}{c}\mathrm{H}_{2} \text { contents* } \\
\text { Winding short-circuit impedance } \\
\text { differences between the initial value } \\
\text { Winding insulation dielectric loss } \\
\text { Initial winding capacitance } \\
\text { differences } \\
\end{array}$ \\
\hline 5 & Partial discharge & $\begin{array}{c}\text { Oil-containing gas * } \\
\text { Oil moisture * } \\
\mathrm{H}_{2} \text { contents* } \\
\mathrm{CH}_{4} \text { contents* } \\
\text { Partial discharge } \\
\text { Winding DC resistance } \\
\end{array}$ \\
\hline 6 & Arc discharge & $\begin{array}{c}\mathrm{H}_{2} \text { contents* } \\
\mathrm{C}_{2} \mathrm{H}_{2} \text { contents* } \\
\text { Winding } \mathrm{DC} \text { resistance mutual } \\
\text { differences } \\
\text { Partial discharge } \\
\end{array}$ \\
\hline 7 & Insulation aging & $\begin{array}{c}\text { furfural contents* } \\
\text { Oil-containing gas * } \\
\text { Cardboard polymerization degree * } \\
\text { Insulating oil dielectric loss } \\
\text { Winding insulation dielectric loss } \\
\text { Volume resistivity }\end{array}$ \\
\hline 8 & $\begin{array}{l}\text { Insulating oil } \\
\text { degradation }\end{array}$ & $\begin{array}{c}\text { Oil-containing gas * } \\
\text { Oil moisture } * \\
\text { Insulating oil dielectric loss } \\
\text { Core insulation resistance } \\
\text { Volume resistivity } \\
\text { Oil Breakdown Voltage } \\
\end{array}$ \\
\hline
\end{tabular}

\section{The Association Rule Theory Calculate Weight COEFFICIENTS INDIVIDUAL STATUS}

The calculation of Individual status weight coefficient has been a difficulty of transformer state evaluation. Currently the main academic areas proposed Grey Correlation Method, and AHP, etc. Gray Correlation Method avoided expert disagreement caused by the redistribution of error, but the method is difficult to determine the resolution factor. Analytic
Hierarchy Process is divided the complex problem into various components of the factors that determine the relative importance of each factor levels by couple comparison, and then determine the overall expert to determine the weight of each factor coefficient. For individual status, the importance of subjective judgment is often no basis, therefore, based on the statistical data, we avoid the subjectivity of expert opinion defects, introduced a weight calculation method based on association rules. Association rules is to find the correlation between different items in the same event, or find the event all the subset of the frequent item or attribute, as well as the correlation between them. According to the definition of related concepts of association rules, Transaction Database recorded as $C, C$ is a subset of transaction $\delta$ 'collection, $C=\left\{\delta_{1}, \delta_{2}, \ldots, \delta_{N}\right\}, N$ is the number of transaction database subsets, A subset of affairs recorded as $\delta_{i}=\left\{x_{1}, x_{2}, \ldots, x_{N}\right\}$, $x$ is called as item, Let $C=\left\{x_{1}, x_{2}, \ldots, x_{j}\right\}$ as all items in the collection $C$,any subset of $x$ means $A$ called as item sets, $|A|=K$ set $A$ is called as $K$ item sets. In the transaction database $C$, Support count the number of items it contains a specific set of transaction $A$ is called $A$ collection of items. Recorded as $\sigma(A)$, in the probability can be expressed as $\sigma(A)=\left|\left\{\delta_{i} \mid A \subseteq \delta_{i}, \delta_{i} \subseteq C\right\}\right|$.

Suppose item sets $A \subset C, B \subset C$, and $A \cap B=\Psi$, then define relational $A \rightarrow B$ as the association rules. $A, B$ turn into respectively and conclusion of the premise of association rules $A \rightarrow B$. Association rules $A \rightarrow B$ 'support is the percentage of the database $C$ contains $A \cup B$. Denoted as

$$
\operatorname{Support}(A \rightarrow B)=P(A \cup B)
$$

At this time, the support is closer to 1 , indicates the connection degree of premise $A$ and conclusion $B$ is higher.

Association rules $A \rightarrow B$ 'Confidence is the percentage of the database $C$ contains $A$ and $B$ at the same time. Means the conditional probability $P(B \mid A)$, donated as

$$
\text { Confidence }(A \rightarrow B)=P(B \mid A)=\frac{P(A \cup B)}{P(A)} \times 100 \%
$$

Confidences represent a credible degree of association rules, which means, the higher the confidences level is, the higher its credibility.

Application of association rules in calculating the weights, we must first consider the issue of its support. According to the definition of support in the transformer condition assessment can be set as

(i) $C=\{$ The i-th comprehensive state is excessive $\}$

(ii) $A_{i, j}=\{\mathrm{j}$-th individual status in i-th com-state is excessive $\}$ 
(iii) $B_{i}=\{$ The i-th comprehensive state malfunction $\}=C_{i}$

Among them, the item set $B_{i}$ and transaction databases $C_{i}$ are equal. This is because there is corresponding relationship with the occurrence of a fault and the comprehensive state quantity to exceed. Therefore, both in the probabilistic calculations can press the same thing to deal with.

$A_{i, j} \rightarrow B_{i}$ ' support can be calculated as follows

$$
\begin{aligned}
& \operatorname{Support}\left(A_{i, j} \rightarrow B_{i}\right)=P\left(A_{i, j} \cup B_{i}\right)= \\
& \frac{\sigma\left(A_{i, j} \cup B_{i}\right)}{\left|C_{i}\right|} \times 100 \%=\frac{\sigma\left(A_{i, j} \cup C_{i}\right)}{\left|C_{i}\right|} \times 100 \%
\end{aligned}
$$

$A_{i, j} \rightarrow B_{i}$ ' confidence can be calculated as follows

$$
\begin{aligned}
& \text { Confidence }\left(A_{i, j} \rightarrow B_{i}\right)=\frac{P\left(A_{i, j} \cup B_{i}\right)}{P\left(A_{i, j}\right)}= \\
& \frac{\sigma\left(A_{i, j} \cup B_{i}\right) \div|C|}{\sigma\left(A_{i, j}\right) \div|C|}=\frac{\sigma\left(A_{i, j} \cup B_{i}\right)}{\sigma\left(A_{i, j}\right)} \times 100 \%
\end{aligned}
$$

Weight coefficients of Individual state quantity can be calculated as follows

$$
m_{i, j}=\frac{C_{i, j}}{C_{i, 1}+C_{i, 2}+\ldots+C_{i, j}+\ldots+C_{i, t_{i}}}
$$

Wherein, $m_{i, j}$ is the weight coefficients of $\mathrm{j}$-th individual status in the i-th comprehensive state, $C_{i, j}$ is the confidence of $\mathrm{j}$-th individual status in the $\mathrm{i}$-th comprehensive state, $t_{i}$ is the number of individual status contained in the i-th comprehensive state.

We use Table I arc discharge as an example to calculate the weight coefficients of individual status.

The comprehensive state includes 4 individual statuses: $\mathrm{H}_{2}$ contents*, $\mathrm{C}_{2} \mathrm{H}_{2}$ contents*. Winding DC resistance mutual differences, Partial discharge. We assume the 4 statuses as $A_{6,1}, A_{6,2}, A_{6,3}, A_{6,4}$, arc discharge malfunction as $B_{6}$, we assumed that there are 1000 data in the total database and 115 arc discharge faults among them. In this 115 faults, the excessive number of $\mathrm{H}_{2}$ contents*, $\mathrm{C}_{2} \mathrm{H}_{2}$ contents*, Winding DC resistance mutual differences, partial discharge are 98, 97, 93,106 . And the total excessive number of $\mathrm{H}_{2}$ contents*, $\mathrm{C}_{2} \mathrm{H}_{2}$ contents*, winding DC resistance mutual differences, partial discharge are 366, 218, 281, 216.

We got that

$$
\begin{aligned}
& B_{6}=115, \sigma\left(A_{6,1}\right)=366, \sigma\left(A_{6,2}\right)=218, \sigma\left(A_{6,3}\right)=281, \\
& \sigma\left(A_{6,4}\right)=216 ; \\
& \sigma\left(A_{6,1} \cup B_{6}\right)=98, \sigma\left(A_{6,2} \cup B_{6}\right)=97, \sigma\left(A_{6,3} \cup B_{6}\right)=93, \\
& \sigma\left(A_{6,4} \cup B_{6}\right)=106 ;
\end{aligned}
$$

Then we can calculate the confidence of $\mathrm{H}_{2}$ contents* as follows

$$
C_{6,1}=\frac{P\left(A_{6,1} \cup B_{6}\right)}{P\left(A_{6,1}\right)} \times 100 \%=\frac{98 / 1000}{366 / 1000} \times 100 \%=26.78 \%
$$

In the same way we can got

$$
C_{6,2}=44.50 \%, C_{6,3}=33.10 \%, C_{6,4}=49.07 \% \text {. }
$$

Then the weight coefficients of individual status with arc discharge can be got as follows

$$
\begin{aligned}
& m_{6,1}=\frac{C_{6,1}}{C_{6,1}+C_{6,2}+C_{6,3}+C_{6,4}}= \\
& \frac{28.78 \%}{28.78 \%+44.50 \%+33.10 \%+49.07 \%}=0.1851
\end{aligned}
$$

In the same way we can got

$$
m_{6,2}=0.2863, m_{6,3}=0.2130, m_{6,4}=0.3157 .
$$

Similarly, other weighting coefficients of individual status can be calculated.

\section{IMPLEMENTATION OF THE ANALYTIC HIERARCHY PROCESS In CALCUlating THE WeIGHT COEFFICIENTS OF COMPREHENSIVE STATE}

Using association rule can achieve better results in the calculation of individual status weight coefficients. But in the view of the comprehensive state[10], according to the seriousness of the fault degree as basis to calculate weight coefficient are usually necessary. In this case the use of expert judgment based on AHP is more appropriate. Therefore, in calculating the amount of a comprehensive state weighting coefficient, I used the Analytic Hierarchy Process.

AHP is roughly divided into five steps[11]: 1.Establish a hierarchy 2.Establish judgment matrix 3.Weighting coefficient Factors calculation 4.Consistency check 5. Determine whether the judgment matrix test by consistency.

\section{Establish a hierarchy}

For transformer, we have been using association rules 
method to calculate the weights of individual status, so here we only need to build the two levels, namely the target layer and solution layer.

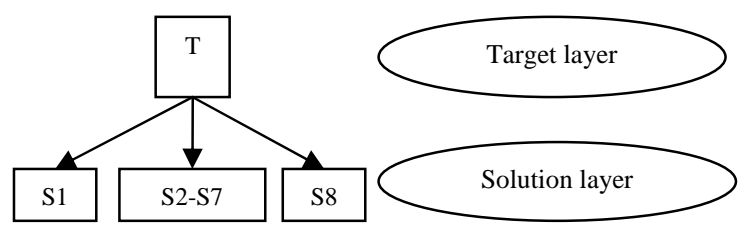

FIGURE I. LEVEL BUILDING.

\section{Establish judgment matrix}

Matrix $T, T_{i j}$ represents the importance of the ratio of the upper layer between $i$ and $j$, the meaning of the factors and the scale has been explained in the table, here to select five scales.

TABLE II. MEANS OF T

\begin{tabular}{|c|c|}
\hline Value of $T_{i j}$ & Means \\
\hline 1 & As important as factor $\boldsymbol{i}$ and $\boldsymbol{j}$ \\
\hline 2 & $\boldsymbol{i}$ is slightly more important than $\boldsymbol{j}$ \\
\hline 3 & $\boldsymbol{i}$ is sorely more important than $\boldsymbol{j}$ \\
\hline 4 & $\boldsymbol{i}$ is extremely more important than $\boldsymbol{j}$ \\
\hline 5
\end{tabular}

S1-S8 represent the 8 comprehensive states follow as: Wet insulation, Core fault, Current loop is overheating, Winding fault, Partial discharge, Arc discharge, Insulation aging, Insulating oil degradation. $S 1-S 8$ can constitute a relatively judgment matrix $T$.

$$
S=\left[\begin{array}{ccccccccc}
T & S_{1} & S_{2} & S_{3} & S_{4} & S_{5} & S_{6} & S_{7} & S_{8} \\
S_{1} & 1 & 1 / 4 & 1 & 1 / 5 & 1 / 3 & 1 / 2 & 1 / 5 & 1 / 4 \\
S_{2} & 4 & 1 & 3 & 1 & 2 & 3 & 1 / 2 & 1 \\
S_{3} & 1 & 1 / 3 & 1 & 1 / 2 & 2 & 2 & 1 / 4 & 1 / 3 \\
S_{4} & 5 & 1 & 2 & 1 & 3 & 2 & 1 / 2 & 1 \\
S_{5} & 3 & 1 / 2 & 1 / 2 & 1 / 3 & 1 & 1 / 2 & 1 / 5 & 1 / 2 \\
S_{6} & 2 & 1 / 3 & 1 / 2 & 1 / 2 & 2 & 1 & 1 / 4 & 1 / 2 \\
S_{7} & 5 & 2 & 4 & 2 & 5 & 4 & 1 & 3 \\
S_{8} & 4 & 1 & 3 & 1 & 2 & 2 & 1 / 3 & 1
\end{array}\right]
$$

3. Weighting coefficient Factors calculation

First, calculating the product of each line elements in Judgment matrix $S$, donated as

$$
L_{i}=\prod_{i=1}^{n} s_{i j}, i=1,2,3, \ldots n
$$

Then, calculating the $\mathrm{n}$ times squaring-roots of each $M_{i}$

$$
\bar{W}_{i}=\sqrt[n]{L_{i}}, i=1,2,3, \ldots n
$$

Wherein, $\mathrm{n}$ is the order of the matrix.

The normalized vector $\left[\bar{W}_{1}, \bar{W}_{2}, \ldots \bar{W}_{n}\right]$, calculated as follows

$$
W_{i}=\frac{\bar{W}_{i}}{\sum_{i=1}^{n} \bar{W}_{i}}
$$

$W_{i}$ is the weight coefficients of each comprehensive state.

According to the above steps, we can calculated each $W_{i}$ for Matrix $S$ as follows

$$
W=\left[\begin{array}{l}
0.0389,0.1610,0.0717,0.1574, \\
0.0595,0.0692,0.2968,0.1455
\end{array}\right]
$$

\section{Consistency check}

After the weight vector $W$ of judgment matrix $S$ was got, consistency on their effectiveness, ensure the effectiveness of the judgment matrix $S$, thus scientifically reflect the relative importance of each comprehensive state.

The maximum characteristic value of judgment matrix $S$ can be calculated as follows

$$
\lambda_{\max }=\sum_{i=1}^{n}(S \cdot W)_{i} / n W_{i}=8.3474
$$

Wherein:

$$
\begin{gathered}
S \cdot W=\left[\begin{array}{cccc}
S_{11} & S_{12} & \cdots & s_{1 n} \\
S_{21} & S_{22} & \cdots & \vdots \\
\vdots & \vdots & \cdots & \vdots \\
S_{n 1} & S_{n 2} & \cdots & s_{n n}
\end{array}\right]\left[\begin{array}{c}
W_{1} \\
W_{2} \\
\vdots \\
W_{n}
\end{array}\right] \\
(S \cdot W)_{i}=s_{i 1} W_{1}+s_{i 2} W_{2}+\cdots s_{i n} W_{n}
\end{gathered}
$$

Calculation consistency index $C I$

$$
C I=\frac{\lambda_{\max }-n}{n-1}=0.1925
$$

$C I$ is equal to 0 means completely consistent. But the matrix order number is larger, $C I$ is equal to 0.1925 is already an ideal data, so the consistency is good enough. 


\section{POWER TRANSFORMER CONDITION ASSESSMENT}

According to AHP and association rules method can establish the appropriate transformer condition assessment system. Assess the state of the system flow chart shown in FIG, specific process consists of the following steps.

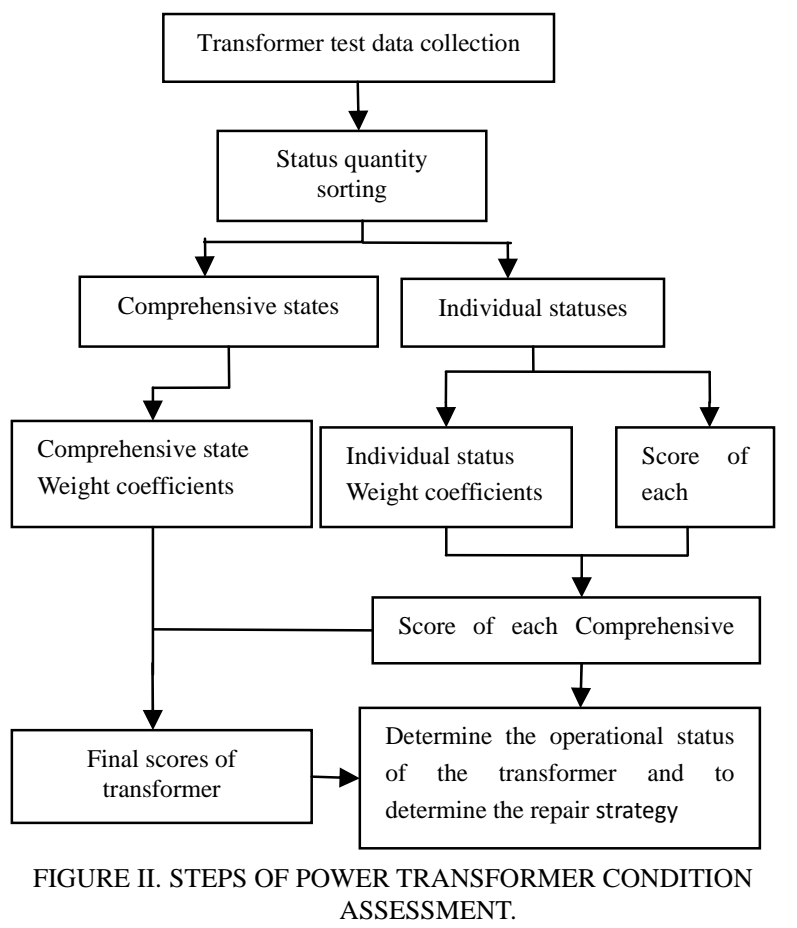

Firstly, each individual status score in comprehensive state is calculated as follows

$$
\begin{gathered}
\text { if }\left|\frac{\left(x_{i j}-x_{I}\right)}{1.6\left(x_{w}-x_{I}\right)}\right|>1 \text {, then }\left|\frac{\left(x_{i j}-x_{I}\right)}{1.6\left(x_{w}-x_{I}\right)}\right|=1 \\
y_{i j}=100\left(1-\left|\frac{\left(x_{i j}-x_{I}\right)}{1.6\left(x_{w}-x_{I}\right)}\right|\right)
\end{gathered}
$$

Wherein, $y_{i j}$ is Score of each Individual statuses, $x_{i j}$ is measured value of Individual statuses, $x_{I}$ is Initial value of Individual statuses, $x_{w}$ is Warning value of Individual statuses

Then, score of each Comprehensive states is calculated according to the Individual status Weight coefficients and score.

$$
y_{i}=\sum_{j=1}^{m_{i}} m_{i j} y_{i j}
$$

Wherein, $y_{i}$ is Score of each Comprehensive states, $m_{i j}$ is
Individual status Weight coefficients, $y_{i j}$ is Score of each Individual statuses.

Finally, final scores of transformer is calculated as follows

$$
T=\sum_{i=1}^{n} w_{i} y_{i}
$$

Wherein, $T$ is the final scores of transformer, $w_{i}$ is Comprehensive state Weight coefficients, $y_{i}$ is Score of each Comprehensive states.

Judge the operating state of transformer according to the final score, and determine the corresponding maintenance strategy. The relationship between with the power transformer condition and the final score are shown in table III.

TABLE III. RELATIONESHIP OF TRANSFORMER CONDITION AND FINAL SCORE

\begin{tabular}{|c|c|c|c|c|}
\hline Final score & $\begin{array}{c}80- \\
100\end{array}$ & $60-80$ & $40-60$ & $0-40$ \\
\hline $\begin{array}{c}\text { Transformer } \\
\text { condition }\end{array}$ & $\begin{array}{c}\text { Nor } \\
\text { mal }\end{array}$ & Careful & Abnormal & Serious \\
\hline
\end{tabular}

\section{EXAMPLE VERIFICATION}

In order to verify the effectiveness of the method proposed in this paper, a transformer substation in the western region of China, for example, a $220 \mathrm{KV}$ main transformer in 2014 a

\begin{tabular}{|c|c|c|c|}
\hline Individual statuses & $\begin{array}{l}\text { measured } \\
\text { value } x_{i j}\end{array}$ & $\begin{array}{l}\text { Warning } \\
\text { value } x_{w}\end{array}$ & $\begin{array}{r}\text { Initial } \\
\text { value } x_{I}\end{array}$ \\
\hline $\begin{array}{c}\text { Insulating oil dielectric } \\
\text { loss } / \%\end{array}$ & 1.3 & 4 & 0.5 \\
\hline Oil moisture */(mg/L) & 11.2 & 25 & 3.5 \\
\hline $\begin{array}{l}\text { Oil Breakdown } \\
\text { Voltage/KV }\end{array}$ & 53 & 35 & 58 \\
\hline Polarization Index & 1.94 & 1.5 & 2.5 \\
\hline $\begin{array}{l}\text { Volume resistivity/ }\left(10^{9}\right. \\
\Omega \cdot m)\end{array}$ & 56 & 3 & 60 \\
\hline $\mathrm{H}_{2}$ content $* /(\mu L / L)$ & 348 & 150 & 6 \\
\hline $\begin{array}{l}\text { Core grounding } \\
\text { current/A }\end{array}$ & 3.8 & 0.1 & 0.01 \\
\hline $\begin{array}{l}\text { Core insulation } \\
\text { resistance/ } M \Omega\end{array}$ & 400 & 100 & 1000 \\
\hline $\mathrm{C}_{2} \mathrm{H}_{6}$ content $* /(\mu L / L)$ & 90 & 65 & 2.3 \\
\hline $\begin{array}{l}\mathrm{C}_{2} \mathrm{H}_{4} \text { content } \\
* /(\mu L / L)\end{array}$ & 56 & 50 & 4.8 \\
\hline $\begin{array}{l}\text { CO relative gas rate } \\
\qquad /(\mu L / L)\end{array}$ & 28 & 100 & 0 \\
\hline $\begin{array}{c}\mathrm{CO}_{2} \text { relative gas rate } \\
* /(\mu L / L)\end{array}$ & 87 & 200 & 0 \\
\hline $\begin{array}{l}\text { Winding short-circuit } \\
\text { impedance difference } \\
\text { between the initial } \\
\text { value/\% }\end{array}$ & 1.3 & 3 & 1 \\
\hline Winding insulation & 0.42 & 0.8 & 0.17 \\
\hline
\end{tabular}
group of experiment data and relevant notice was shown in the table[12].

TABLE IV. TESTING DATA OF TRANSFORMER 


\begin{tabular}{|c|c|c|c|}
\hline dielectric loss $/ \%$ & & & \\
\hline $\mathrm{C}_{2} \mathrm{H}_{2}$ content $* /(\mu \mathrm{L} / \mathrm{L})$ & 0 & 5 & 0 \\
\hline Partial discharge/pC & 88 & 500 & 30 \\
\hline $\begin{array}{c}\text { Oil-containing gas } \\
* /(\mu L / L)\end{array}$ & 1.6 & 3 & 1 \\
\hline $\mathrm{CH}_{4}$ content $/(\mu L / L)$ & 20 & 100 & 8.7 \\
\hline $\begin{array}{c}\text { furfural } \\
\text { contents } *(\mu L / L)\end{array}$ & 0.32 & 0.2 & 0 \\
\hline $\begin{array}{c}\text { Cardboard } \\
\text { polymerization degree } \\
* /(\mu L / L)\end{array}$ & 300 & 250 & 1000 \\
\hline
\end{tabular}

[11] Guo, J., et al., Green design assessment of electromechanical products based on group weighted-AHP. ENTERPRISE INFORMATION SYSTEMS, 2015. 9(8): p. 878-899.

[12] LI Li.,et al., A Condition Assessment Method of Power Transformers Based on Association Rules and Variable Weight Coefficients. Proceedings of the CESS, 2013(24): p.152-159.

Follow the steps described in this paper to analyze the above data, it is concluded that the transformer final score is $T=41.67$, the insulation aging scoring just 38.25 points, so that, the transformer has serious insulation aging problem, need to take immediate measures, which is consistent with actual situation.

\section{ACKNOWLEDGMENT}

This work is supported by National Natural Science Foundation of China under Grant No.61472128and 61173108, and Hunan Provincial Natural Science Foundation of China No.14JJ2150.

\section{REFERENCES}

[1] Sica, F.C., et al., A cognitive system for fault prognosis in power transformers. ELECTRIC POWER SYSTEMS RESEARCH, 2015. 127: p. 109-117.

[2] Bicen, Y. and F. Aras, A robust algorithm based on a failure-sensitive matrix for fault diagnosis of power systems: an application on power transformers. TURKISH JOURNAL OF ELECTRICAL ENGINEERING AND COMPUTER SCIENCES, 2015. 23(1): p. 298315.

[3] Subbalakshmi, C., et al., A Method to Find Optimum Number of Clusters Based on Fuzzy Silhouette on Dynamic Data Set, in Procedia Computer Science, P. Samuel, P. Samuel^Editors. 2015, ELSEVIER SCIENCE BV: AMSTERDAM. p. 346-353.

[4] Chu, K.J. and M. Tan, Assessment of sediment quality in Jiangsu coastal ocean based on grey clustering method, in Applied Mechanics and Materials, S. Feroz, S. Feroz $\wedge$ Editors. 2014, TRANS TECH PUBLICATIONS LTD: STAFA-ZURICH. p. 266-271.

[5] Chen, G., T.D. Bui and A. Krzyzak, Sparse support vector machine for pattern recognition. CONCURRENCY AND COMPUTATIONPRACTICE \& EXPERIENCE, 2016. 28(7): p. 2261-2273.

[6] Chang, J., et al., THE ASSESSMENT OF TRANSFORMER STATUS BASED ON GRAY THEORY, in Applied Mechanics and Materials, S.B. Choi, P. Yarlagadda and M. AbdullahAlWadud, S.B. Choi, P. Yarlagadda and M. AbdullahAlWadud^Editors. 2014, TRANS TECH PUBLICATIONS LTD: STAFA-ZURICH. p. 1147-1152.

[7] Wang, D.W. and L.X. He, A Fault Diagnosis Model for Power Transformer Using Association Rule Mining-Based on Rough Set, in Applied Mechanics and Materials, P. Yarlagadda, S.B. Choi and Y.H. Kim, P. Yarlagadda, S.B. Choi and Y.H. Kim^^ditors. 2014, TRANS TECH PUBLICATIONS LTD: STAFA-ZURICH. p. 1169-1172.

[8] Xin, H.H. and F.F. Wang, Analysis on the influence factor of power transformers' quality based on the AHP. 2014, WORLD PUBLISHING CORPORATION: BEIJING. p. 203-208.

[9] Lee, L., et al., Condition Assessment of Power Transformers Using a Synthetic Analysis Method Based on Association Rule and Variable Weight Coefficients. IEEE TRANSACTIONS ON DIELECTRICS AND ELECTRICAL INSULATION, 2013. 20(6): p. 2052-2060.

[10] Bartlomiejczyk, M., M. Gutten and S. Hamacek, Analysis of transformer state by fuzzy TOPSIS and AHP method, in International Scientific Conference on Electric Power Engineering. 2014, IEEE: NEW YORK. 